\title{
EL MUSEO TÚCUME Y LA NUEVA MUSEOLOGÍA
}

\author{
THE TÚCUME MUSEUM AND THE NEW MUSEOLOGY
}

Luis Alfredo Narváez Vargas ${ }^{1}$

\begin{abstract}
El Museo de Túcume fue abierto en el año 1992 y reconocido en 1994 como una institución pública dependiente del Instituto Nacional de Cultura (INC), hoy Ministerio de Cultura del Perú. Es consecuencia de un proyecto de investigación arqueológica llevado a cabo entre 1989 y 1994 bajo el patrocinio del famoso biólogo y explorador noruego Thor Heyerdahl, y financiado por el Museo Kon Tiki de Oslo-Noruega, en convenio con el INC. Desde sus inicios, el museo tuvo un marcado interés etnográfico que lo llevó a un acercamiento permanente con diversas expresiones de la cultura tradicional local, proponiendo un diálogo entre el pasado y el presente, no solo desde sus exhibiciones sino en el fomento de las relaciones comunitarias. Su quehacer ha sido compatible con las tendencias de la Nueva Museología francesa de la segunda mitad del siglo XX, generando un modelo de gestión pionero y novedoso para su tiempo en el Perú. De este modo, su eje de acción: territorio, patrimonio y comunidad ha caracterizado sus relaciones comunitarias y definido su interés científico, arribando a la organización de un ecomuseo, como solitario ejemplo de esta metodología en el Perú. Sin embargo, esta experiencia pone en relieve el debate sobre los criterios de sostenibilidad en la gestión del patrimonio cultural en general y en el arqueológico en particular.
\end{abstract}

Palabras claves: patrimonio cultural, comunidad y sostenibilidad, ecomuseo, Nueva Museología, museología tradicional.

The Túcume Museum was opened in 1992 and in 1994 it was granted the status of public institution dependent on the National Institute of Culture (NIC), which is today the Ministry of Culture of Peru. The museum is the result of an archaeological research project carried out between 1989 and 1994 under the sponsorship of the famous Norwegian biologist and explorer Thor Heyerdahl, and funded by the Kon Tiki Museum in Oslo under an agreement with the NIC. From its origins, the museum had a strong ethnographic interest which brought it closer to diverse expressions of the local traditional culture, proposing a dialogue between the past and the present not only from its exhibitions but also from the development of community relations. Its activities have always been in line with the tendencies of the French New Museology from the second half of the XX century, creating a pioneering and innovative management model for its time in Peru. In this way, the main line of action including territory, heritage and community has characterized its community relations and defined its scientific interest, leading to the organization of an ecomuseum as the only example of this methodology in Peru. Nevertheless, this experience highlights the debate about the sustainability criteria in the management of cultural heritage in general and of archaeological heritage in particular.

Key words: Cultural heritage, community and sustainability, ecomuseum, New Museology, traditional museology.

Túcume es uno de los 11 distritos rurales de la provincia de Lambayeque, departamento del mismo nombre, en la costa norte del Perú (Figura 1). Se ubica en la parte baja del Valle de La Leche, uno de los ríos secos que se activan durante las lluvias estacionales que se producen en las alturas vecinas de los Andes occidentales, sin las cuales la agricultura costera no existiría. Cíclicamente, la zona costera se ve afectada de modo severo por el fenómeno deEl Niño, produciéndose lluvias torrenciales altamente destructivas. Este distrito es conocido por el sitio arqueológico ubicado en torno a Cerro Purgatorio (Figura 2), una de las montañas simbólicamente más importantes en esta región. Dicho sitio es comúnmente conocido como las Pirámides de Túcume, las Pirámides de Cerro Purgatorio o Cerro La Raya.
En 1987 se descubrió accidentalmente una tumba moche (100 AC - 600 DC) muy rica, a consecuencia de la búsqueda de tesoros motivada por el comercio ilegal de antigüedades, muy común en esta región. Este asunto policial involucró a Walter Alva, el único arqueólogo local en ese tiempo, que organizó un proyecto de investigación y salvamento de la plataforma funeraria. Después de varios años de dedicada labor, los frutos fueron sorprendentes, pues se descubrió la tumba intacta de un personaje perteneciente a la élite moche ricamente ataviado, con una gran cantidad de objetos, joyas de metales preciosos y ornamentos muy diversos (Alva s/f). Posteriormente, se descubrieron otras tumbas, mostrando un conjunto notable que hizo posible la concreción de un museo especializado: Museo de las Tumbas Reales de Sipán en 2002, y luego

1 Museo Túcume - UE 005 Ministerio de Cultura, Lambayeque, Perú. luisalfredonarvaez@hotmail.com

Recibido: enero 2018. Aceptado: diciembre 2018.

http://dx.doi.org/10.4067/S0717-73562019005001601. Publicado en línea: 23-julio-2019. 


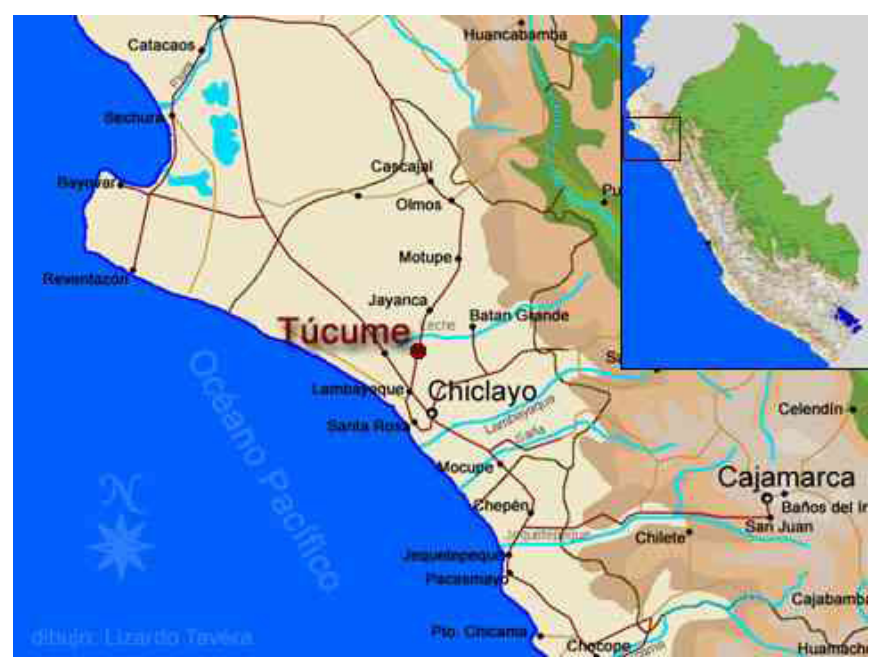

Figura 1. Localización de Túcume en la costa norte de Perú. Tomado de http://www.arqueologiadelperu.com.ar/tucume.htm. Dibujo de Lizardo Tavera Vega.

Location of Túcume in the Northern Coast of Peru. http://www. arqueologiadelperu.com.ar/tucume02.jpg Drawn by Lizardo Tavera Vega.

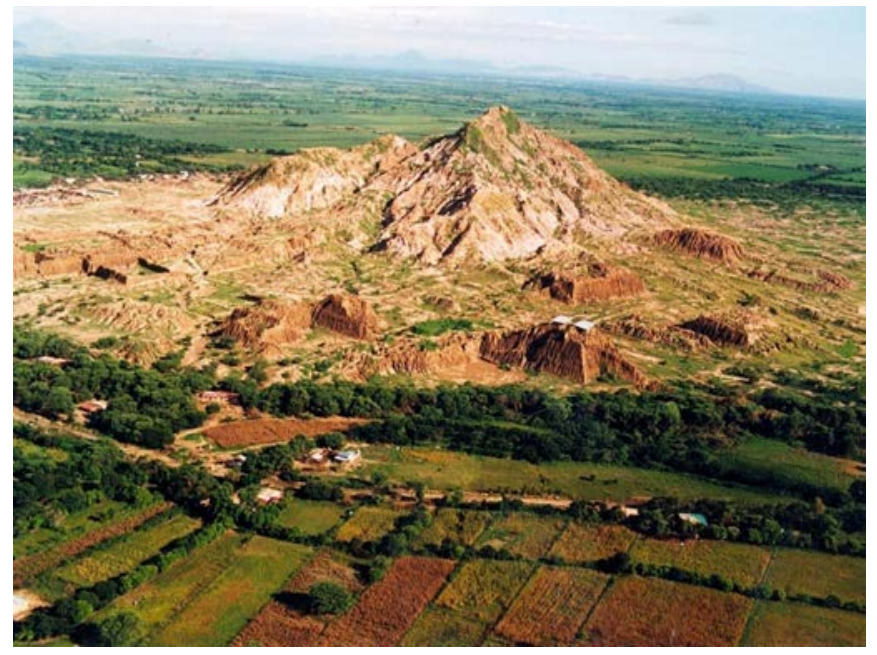

Figura 2. Pirámides de Túcume y Cerro Purgatorio con la ubicación del museo. Túcume pyramids and Purgatorio Hill with the location of the museum. 
del Museo de Sitio de Huaca Rajada-Sipán en 2009, que pertenecientes a la Unidad Ejecutora 005 del Ministerio de Cultura.

Pronto la noticia recorrió el mundo, logrando la atención de medios internacionales y publicaciones de ciencia popular que generaron el interés del famoso biólogo y explorador noruego Thor Heyerdahl, que hizo rápidamente un viaje a Perú, a Lambayeque, quedando asombrado por el hallazgo. Visitó varios sitios monumentales y finalmente llegó a Túcume, decidiendo organizar un proyecto científico con participación de arqueólogos de varias nacionalidades. El convenio que hizo posible este proyecto autorizó la ejecución de excavaciones científicas por un lapso de cinco años, que culminaron al finalizar el primer semestre de 1994.

En esos años, la arqueología peruana estuvo basada en proyectos extranjeros que realizaban excavaciones y las cubrían al término de cortas temporadas. El estudio final generaba artículos científicos y pocas veces libros de síntesis, que circulaban únicamente en medios académicos totalmente alejados de las poblaciones locales y la sociedad en su conjunto. Solo algún hallazgo de importancia podía recibir atención de diversos medios y merecer reportajes o notas periodísticas. La presencia de Sendero Luminoso y la severa crisis económica que azotó al país entre los años 1980 al 2000 expulsó a los proyectos extranjeros, quedando un pequeño grupo de investigadores peruanos que no solo hicieron posible la organización de proyectos científicos de alto nivel, largo aliento y con grandes aportes sino, por sobre todo, iniciaron procesos complejos de inserción social, de puesta en valor y de un mayor acercamiento de la ciencia a la sociedad.

\section{El Inicio del Proceso}

El Proyecto Arqueológico Túcume (PAT), patrocinado por el Museo Kon Tiki gracias a Thor Heyerdahl, fue codirigido por Alfredo Narváez y Daniel Sandweiss $(1990 ; 1991)$ y luego dirigido por Alfredo Narváez hasta su culminación en 1994 (Heyerdahl et al. 1994; 1995). A las investigaciones arqueológicas le sucedieron diversos registros paralelos en el campo etnográfico, debido a nuestro interés profesional en la cultura tradicional que mostraba, en los vecinos de la comunidad, diversas expresiones de continuidad entre el pasado prehispánico y la vida contemporánea. Este acercamiento, desde el inicio del proyecto arqueológico, generó la posibilidad de proponer conexiones entre la comunidad local y los avances y resultados de la investigación. Al respecto quisiera indicar algunos ejemplos:

- El hallazgo de contextos funerarios prehispánicos asociados a instrumentos de uso actual fue notable especialmente en el campo de los textilerias. Las esposas, madres o hermanas de nuestros trabajadores conocían la técnica del telar de cintura, cuya práctica milenaria estaba en franco proceso de desaparición, manteniendo la producción de alforjas y fajas o cinturones. Las tejedoras de hoy nos ayudaron a comprender aspectos como la función de diversos instrumentos y objetos, su ubicación en el proceso productivo, la división y especialización del trabajo, las dimensiones de los productos textiles en función del tamaño de los instrumentos de producción, así como la importancia, uso y función de materiales conexos como la localmente llamada "tiza de huaca" que, al untarse con los dedos, permite conseguir hilos cada vez más finos.

- La identificación de diversas especies vegetales, animales o marinas procedentes de las excavaciones, como fue el caso de plantas medicinales identificadas por curanderos locales que participaron como auxiliares de campo durante las excavaciones.

- Las técnicas de construcción, especialmente las referidas a edificaciones de barro y quincha, muy populares aun en ese momento en el ámbito rural.

- Las tradiciones orales relacionadas con la naturaleza como las montañas, animales silvestres y diversos aspectos de la cosmovisión, destacando elementos celestes como la luna, el sol, la vía láctea y algunas constelaciones. También la relación entre la producción agrícola y las fases de la luna o su grado de inclinación, o los cultivos de género y la luna o la puesta del sol, entre muchos otros asuntos.

- El conocimiento de los maestros curanderos y la medicina tradicional expresada en un amplio abanico de prácticas, como las "mesas" ceremoniales, y especialidades como "sobanderos", parteras, hueseros, rezadores, santiguadores y los que leen las entrañas del cuy y la suerte (sorteo), entre las más importantes.

- La gastronomía y la persistencia del uso ancestral del maíz (especialmente para la producción de chicha de jora), leguminosas y calabazas, a los que se han agregado diversos productos y técnicas orientales, europeas y africanas, que hoy forman parte del núcleo de la cultura tradicional. Nos llamóla atención la cocina subterránea conocida como "hornado", que se encontraba en proceso de desaparición, utilizada solamente para momentos festivos.

- Las expresiones de religiosidad popular basada en íconos cristianos, en particular el culto mariano de imágenes dobles ${ }^{1}$, asociadas con el Cerro La Raya que se conoce, además, como Cerro Purgatorio, indicando con ello la enorme impronta europea en el aspecto ideológico (Narváez 2000a). Este tema se relaciona también con ritmos y música (que fusiona elementos de diversa procedencia; española, árabe, 
andina) que acompañan la Danza de Diablicos, una expresión española a la que se le han agregado muy sutiles elementos del pasado prehispánico (Narváez 2014).

Desde una perspectiva antropológica, cada uno de estos ejemplos constituye parte de un complejo cultural cuya especial importancia radica en el diálogo y sintonía que establece con el pasado prehispánico y su evolución en el tiempo hasta nuestros días. Esta mirada desde la antropología generó en la visión del proyecto de museo una propuesta distinta a la convencional y tradicional de los museos arqueológicos.

\section{Los Museos Arqueológicos}

Esta mirada convencional hizo de las exhibiciones un discurso que, en muchas ocasiones, iniciaba con el rigor de los cuadros cronológicos difíciles de asimilar, utilizando términos muy especializados y poco efectivos en términos de comunicación con el público, seguido de fases, sub fases de estilos o periodos poco entendibles. Estas exhibiciones, en realidad, despertaban interés por objetos notables de muy alto valor estético, propiciando su admiración como obras de arte. Al mismo tiempo, los museos arqueológicos utilizaron la curiosidad del visitante por la muerte, mostrando cuerpos momificados o esqueletos humanos. Por otro lado, tales museos exhibían el pasado no solamente como estancos en la evolución social, sino además sin ninguna relación con nuestra vida. Las "culturas", como lo ha mencionado de modo reiterado Luis Lumbreras, pareciera que se acabaron con el pasado prehispánico, pues el término desaparece para los especialistas cuando se refieren a la época Colonial, vista como un momento aciago y oscuro, salpicado de momentos de subversión liberadora que dieron paso a la república. El discurso alrededor de lo enigmático y misterioso del pasado a través de los objetos, genera al mismo tiempo diversas formas de mistificarlo y sobredimensionarlo, incluyendo teorías como el "socialismo incaico" y, aún a fines del siglo XX, creaciones "épicas" y poéticas sobre la "gloria" del pasado, cuyos elementos icónicos se convierten en emblemas de corrientes políticas o culturales de espíritu "nacionalista".

Respecto de la gestión propiamente dicha, muchos de estos museos arqueológicos estuvieron preocupados casi exclusivamente en los aspectos de equipamiento, tratamiento de colecciones o investigaciones científicas cuando esto era posible, generalmente por la voluntariosa gestión de sus directores mas no por políticas estatales de fomento a la cultura o la conservación del patrimonio. Todo ello se enmarcaba, además, en el viejo concepto decimonónico del museo como una especie de templo que se expresa en edificios grandes y costosos, como enormes catedrales, que albergan colecciones de bienes generalmente de élite y para un público al principio especializado, culto y conocedor, que a partir del despegue de la economía de post guerra en Europa se transformaría en una enorme masa de turistas que circulan por el mundo.

Tales museos iniciaron como repositorios de obras de arte de interés para especialistas, coleccionistas y lo más alto de las clases sociales, como la nobleza de los estados imperiales en Europa y luego las élites industriales, financieras e inmobiliarias emergentes en muchas partes del mundo. Con ello se favoreció un inmenso mercado ilegal de antigüedades y obras de arte que propició la devastación de numerosos sitios patrimoniales en todo el globo, especialmente en los países del hemisferio sur.

\section{Los criterios de conservación del patrimonio}

En este contexto, la conservación del patrimonio arqueológico estuvo basada exclusivamente en el aspecto normativo altamente coercitivo: el patrimonio se defiende porque la ley lo ordena, incluyendo la persecución y la violencia desde el Estado. La preocupación se centró en los monumentos que se convirtieron en un fin en sí mismos, sin interesar sus entornos sociales y territoriales. Las necesarias áreas intangibles se vuelven auténticas barreras o muros que aíslan los monumentos de la comunidad y no se comportan como puentes de diálogo y entendimiento social. Contradictoriamente el Estado mismo, a través de sus autoridades, se encargaba de oficializar asentamientos que invadían zonas arqueológicas construyendo escuelas del Ministerio de Educación sobre plataformas arqueológicas, recibiendo a poblaciones que huían de zonas inundadas por lluvias torrenciales para reasentarlas sobre estos sitios que se encontraban "disponibles", "sin uso" y en terrenos más elevados, o utilizándolos como canteras para materiales de construcción o relleno de vías de acceso en zonas inundadas. Cada uno de estos casos caracteriza la problemática histórica del patrimonio arqueológico de Túcume. Precisamente el museo actual ha sido construido simbólicamente en el corazón de la destrucción de unas 10 ha del monumento, organizada y ejecutada por el Estado, para obtener rellenos durante las inundaciones producidas por El Niño del año 1983.

El criterio de aplicación ciega de las normas bajo el imperio de la ley, coexistía paradójicamente con la ausencia de abogados especialistas que pudieran defender acertadamente el patrimonio arqueológico frente a un sistema judicial corrupto e incapaz de hacer cumplir la norma. Este escenario incluye a coleccionistas de tesoros antiguos, de marcada 
influencia social y política en las más altas esferas del Estado y el gobierno, que generaron durante toda la república el mercado necesario para alentar el trabajo destructivo de huaqueros y profanadores. Una sociedad caracterizada por el latifundismo como eje con los llamados "barones" del algodón y el azúcar que generaron un sistema de privilegios de profundas raíces sociales. Obviamente en este contexto el ejercicio de la ley para conservar el patrimonio era poco exitoso, involucrando procesos largos de alto costo que no resolvían el problema, lo acrecentaban.

En tales circunstancias, el patrimonio arqueológico tenía una valoración muy alta solamente para un pequeño y reducido grupo de especialistas y algunas personas "letradas" y "cultas", conocedoras de los secretos de la historia y los exotismos que se promueven desde la arqueología. El patrimonio arqueológico y los museos, por lo tanto, terminaban siendo considerados de muy poco interés para el común de las personas, mucho menos para las poblaciones rurales y campesinas o los migrantes de la sierra vecina, masa de pobres y desocupados atraídos por el desarrollismo costeño de la época. Las huacas, además, eran vistas como un lastre para el desarrollo urbano y un problema para la expansión de campos de cultivo. Su destrucción se podía considerar rentable y una oportunidad para obtener objetos de valor, literalmente tesoros escondidos, siguiendo una tradición y especialidad que viene desde la época colonial cuando se organizaban empresas para explotar huacas (Zevallos Quiñones 1994).

De tal suerte, la conservación de estos monumentos termina siendo del interés de un puñado de especialistas a los que se agregan pronto los empresarios del turismo, actividad promovida y vista como de lujo, propia de personas con dinero y tiempo. De este modo, el patrimonio arqueológico y los museos se convierten, en la percepción popular, en un espacio para extranjeros que pueden pagar las tarifas de ingreso. El término extranjero es visto como un paradigma, pues se relaciona con países desarrollados y "ricos". Escuché reiteradamente a especialistas de turismo, en talleres formales, calificar a los viajeros como "billeteras andantes", promoviendo políticas de Estado para fomentar la visita de turistas ricos, que "realmente contribuyan a dinamizar la economía" por su alta capacidad de gasto. Por ello se entiende que algunos museos arqueológicos, en países pobres como el nuestro, celebren con programas especiales la llegada del "turista un millón" como medida del éxito obtenido, promoviendo la construcción de nuevos museos justamente para "desarrollar el turismo". En la otra orilla, las poblaciones rurales alejadas de los entornos urbanos refuerzan la imagen de museos y monumentos arqueológicos como un asunto de interés para turistas, especialmente extranjeros, acrecentando su alejamiento hacia estos espacios.

\section{Conceptos alternativos de gestión y la creación del Museo Túcume}

Esta visión imperante en muchos museos tiene su paralelo en la preocupación mundial por la conservación de los monumentos, que fue evolucionando favorablemente con el tiempo. Los efectos devastadores sobre el patrimonio arquitectónico y las colecciones de arte durante las guerras mundiales en Europa, movilizaron al mundo en la procuración de su salvamento y protección. Esto se hizo evidente en documentos como la Carta de Atenas (1931) y la Carta de Venecia (1961) que muestran justificadamente una preocupación por los monumentos en sí mismos. Posteriormente, la normativa internacional va asumiendo criterios novedosos como los que se incorporan en la Carta de 1990 del Consejo Internacional de Monumentos y Sitios (ICOMOS, por sus siglas en inglés), que promueve la "gestión integrada" del patrimonio arqueológico, abriendo esta responsabilidad hacia otros sectores de la sociedad. En este proceso es necesario señalar la importancia que tuvo la Cumbre de Río de Janeiro para el mundo (1992), pues se sentaron las bases para promover el "desarrollo sostenible", hoy adoptado en la legislación de todos los países. La famosa Agenda 21 señala pautas innovadoras respecto de la industria de viajes y turismo, incluidas en el documento "Hacia el Desarrollo Sostenible del Medio Ambiente". En él, el concepto del turismo evoluciona desde el liberalismo de la empresa, preocupada únicamente por calidad del servicio, un turismo masivo y mayores ganancias (aun a costa de la destrucción o deterioro de la cultura tradicional y el ambiente), hacia un enfoque que incorpora a las comunidades locales, redistribuye beneficios, respeta sus tradiciones y privilegia la conservación de los recursos y su ambiente. La Agenda 21 promueve también la educación, la conciencia pública y la concertación en la búsqueda del desarrollo sostenible.

Sobre esta base, en el año 1994 a través de la Carta de Nara, el ICOMOS hizo explícita la necesidad de promover el rol de las comunidades como corresponsables de patrimonio cultural y su administración. Más adelante, la Declaración de Sian en el año 2005 puso especial énfasis en la conservación del "entorno", abriendo un espacio importante respecto del territorio relacionado con los sitios patrimoniales. Esta declaración hace especial énfasis además en la necesidad de trabajar con las comunidades locales. La documentación al respecto es hoy abundante, reiterándose la importancia de la vinculación social con el patrimonio y la necesidad de democratizar su gestión, con elementos de apertura y de inclusión como ejes de una nueva política 
desde el sector cultura. Sin embargo, a pesar de lo avanzado, los conflictos entre los sectores de turismo y cultura en nuestra región eran notorios y públicos aun a fines del siglo XX. La integración y concertación con otros sectores del Estado o con las comunidades locales alrededor de la conservación del patrimonio arqueológico eran aspectos casi inexistentes. No podemos dejar de mencionar la Mesa de Santiago (1972) organizada por el Consejo Internacional de Museos (ICOM, por sus siglas en inglés), que plantea un museo "integral" desde una perspectiva interdisciplinaria. Por diversas razones que no es el caso de discutir aquí, estas importantes y renovadoras reflexiones no llegaron al Perú, a pesar de la presencia de profesionales peruanos en dicho evento. En Chile tampoco tuvieron un impacto importante, pues casi inmediatamente el golpe de estado y la dictadura militar lo impidieron.

Este es el contexto histórico en el que decidimos organizar el Museo Túcume. Cabe decir que sacar adelante un nuevo museo en nuestra región significó muchas responsabilidades $\mathrm{y}$, al mismo tiempo, muchas dificultades por las condiciones del país. Mediante la Resolución Jefatural $\mathrm{N}^{\circ} 240$ del 22 de agosto de 1994, el Instituto Nacional de Cultura (INC) reconoció al Museo de Sitio Túcume, nombrando a Alfredo Narváez Vargas como su primer director en condición $A d$ Honorem, manteniendo tal estatus hasta el año 2001.

En realidad, el museo había nacido dos años antes en el seno del Proyecto Arqueológico Túcume (1992), con una exhibición que se organizó en dos ambientes contiguos que servían como almacenes de material arqueológico y herramientas de trabajo para las excavaciones. El primer guion museográfico convirtió estos espacios en salas, comunicadas por un corredor central que las independizaba. $\mathrm{La}$ primera sala estuvo dedicada a los aspectos del territorio y la segunda a presentar un diálogo entre el pasado prehispánico y las expresiones actuales del patrimonio. En el primer caso, se utilizaron vitrinas y dioramas relacionados con el ecosistema del bosque seco y sus principales expresiones de flora y fauna. Combinando el trabajo de artistas plásticos y biólogos taxidermistas, se mostraron aves, reptiles y mamíferos menores. Se incluyeron adicionalmente artefactos que ejemplificaban la cultura campesina del bosque seco, haciendo énfasis en el uso de instrumentos de madera de algarrobo (pilones, batanes, despancadores). Tabiques de caña y barro fueron usados como soportes de la exhibición, y se mostraron comparaciones entre adobes prehispánicos y contemporáneos, además de maquetas con reproducciones de relieves prehispánicos en barro. Al mismo tiempo, se utilizaron objetos diversos de calabazas y cestería, construyéndose una cocina sobre el "tabanco" y una "taberna" campesina, en instalaciones a escala 1/1. La taberna era utilizada por la esposa del guardián del museo para producir chicha de maíz para uso cotidiano. Una sección de interés etnográfico fue la de los "crisoles", pequeñas vasijas arqueológicas en miniatura sin tratamiento de superficie ni acabados especiales, que aparecían en gran cantidad como ofrendas de las tumbas prehispánicas. La sección etnográfica de la exhibición mostraba el uso actual de estas pequeñas vasijas como calentadores de líquidos, especialmente de la chicha de jora, no solo en los ambientes domésticos de la vivienda rural sino además en los establecimientos públicos de venta de chicha y "piqueos".

La segunda sala incluía varios saberes ancestrales, concentrándose en una gran vitrina de textiles con los instrumentos encontrados en las excavaciones arqueológicas al lado de los telares de hoy, incluyendo el proceso productivo, el uso de algodón nativo y los más importantes productos actuales: alforjas y fajas. Una sección adicional estuvo relacionada con los hallazgos de semillas de frutos, huesos de cuy, espinas de pescado y conchas de mariscos colocados dentro de recipientes, todo ello también hallado durante los trabajos en el sitio. Así, la comunidad comprendía mejor el origen de su gastronomía y los productos actuales del mercado local.

Cada una de las salas mostraba además el paisaje pero especialmente a los campesinos del entorno, que podían reconocerse o reconocer a familiares, amigos o vecinos, asunto poco común en los museos arqueológicos del Perú. Habíamos generado una propuesta que calzaba bien con los postulados de la Nueva Museología francesa formulada y desarrollada por Henry Rivière (1993) y Hughes de Varine-Bohan (1985). Conjugamos los conceptos de territorio, patrimonio y comunidad alrededor de un proyecto de museo en las difíciles circunstancias sociales, económicas, de violencia política, de epidemias derivadas de la extrema pobreza y la ausencia de servicios básicos. En estas condiciones se nos cerraban las puertas del incipiente turismo regional, motivado especialmente por el hallazgo de la famosa tumba de Sipán y el Museo Brüning, un edificio con modernas líneas propias de la década de los 60, ubicado en la capital provincial. A ambos espacios, no obstante, se agregaba este naciente y pequeño museo rural en Túcume.

Bajo estos conceptos, la ecuación tradicional de un edificio prominente y costoso cedió paso a un edificio sencillo, hecho con técnicas y materiales nativos y de uso campesino tradicional. La colección dejaba de basarse en obras de arte u objetos de gran valor por sus elementos estéticos, y se abría un espacio a la continuidad cultural con objetos sencillos abordados desde una óptica antropológica, generando un diálogo entre el museo, la comunidad, su territorio y la historia 
del mismo. Cerro Purgatorio no solamente era un elemento central del asentamiento arqueológico, sino especialmente un eje simbólico en la cosmovisión campesina local que incluía diversos elementos de la ideología cristiana europea. Históricamente, Cerro Purgatorio fue un sitio dominante en el paisaje de la parte baja del Valle La Leche y un referente actual de mucha importancia para las ceremonias chamánicas que lo consideran aún hoy como un hito propiamente dicho.

En el inicio de la labor del Museo Túcume, dada la escasez de recursos financieros, uno de los proyectos de investigación más importantes estuvo orientado a la documentación y registro de la tradición oral campesina, tarea que se inició en 1990, en el seno del Proyecto Arqueológico y continuó hasta el año 2000, cuando se logró la publicación del primer trabajo de investigación. Se trata de un libro, enfocado en el territorio, la comunidad y su patrimonio, realizado, con el auspicio del Centro Cultural de la Abadía de Daoulas en Finistère, - Francia (Narváez 2000a). Este proyecto implicó un constante vínculo con diversos actores de la comunidad local y comunidades vecinas, incluyendo al final, el área rural de cinco valles de Lambayeque: Zaña, Chancay, Reque-Lambayeque, La Leche, Motupe y Olmos. Solo quedó pendiente el valle de Cascajal en el extremo norte.

El paulatino cambio y la mejora de las condiciones socioeconómicas y políticas en el país, implicaron no solo un mayor interés por invertir en la infraestructura del museo sino también cambios en la infraestructura comunitaria: nuevos sistemas de comunicaciones, de redes de agua, desagüe y sistemas de electrificación mejoraron notablemente la vida cotidiana. El museo creció y en 1994 se inauguró una magnífica sala de exhibiciones siguiendo el patrón arquitectónico de las antiguas "ramadas" coloniales, basadas en el uso de adobe, barro, caña y una nave con doble hilera de columnas de horcones de algarrobo (Figura 3). Las mejoras también abarcaron los espacios públicos: servicios higiénicos, un anfiteatro, zonas de descanso y señalización. Las dos primeras salas originarias del museo quedaron como Salas Temporales, que desde su inauguración en 1996 hasta 2012, mantuvieron la exposición "Mil Años de Tradiciones Tucumanas", presentando elementos de continuidad entre el pasado y el presente.

El año 1998 fue importante, pues se concretó el aporte inglés de becas para un posgrado con especialización en la gestión del patrimonio, que tuvo lugar en el Durrel Institute for Conservation and Ecology (DICE) de la Escuela de Antropología de la Universidad de Kent en Canterbury, Inglaterra. Estos estudios no solo permitieron asumir con mayor rigor académico las tareas relacionadas con el museo y el monumento, sino también disponer de un primer documento de gestión plasmado en la tesis de maestría titulada "Incorporación de la Comunidad Local en la Gestión del Patrimonio Cultural. Caso de Túcume. Lambayeque, Perú” (Narváez 2000b). Como documento de investigación y propuesta, se nutrió de una evaluación con encuestas y entrevistas que dieron lugar a la organización de un Comité para la Gestión del Patrimonio y el Desarrollo Turístico de Túcume (CGDT), el cual incorporó formalmente a un grupo de pobladores en las tareas de gestión. Allí estuvieron integrados el alcalde, el teniente gobernador, maestros de escuelas y líderes locales trabajando del lado del museo, preocupándose no solamente de los problemas coyunturales ocasionados por el fenómeno El Niño en 1998, sino por dar respuestas positivas en torno a diversos aspectos productivos y educativos vinculados con la gestión del patrimonio.

Derivado de este proceso, se estableció formalmente la Oficina de Educación para la Conservación y se
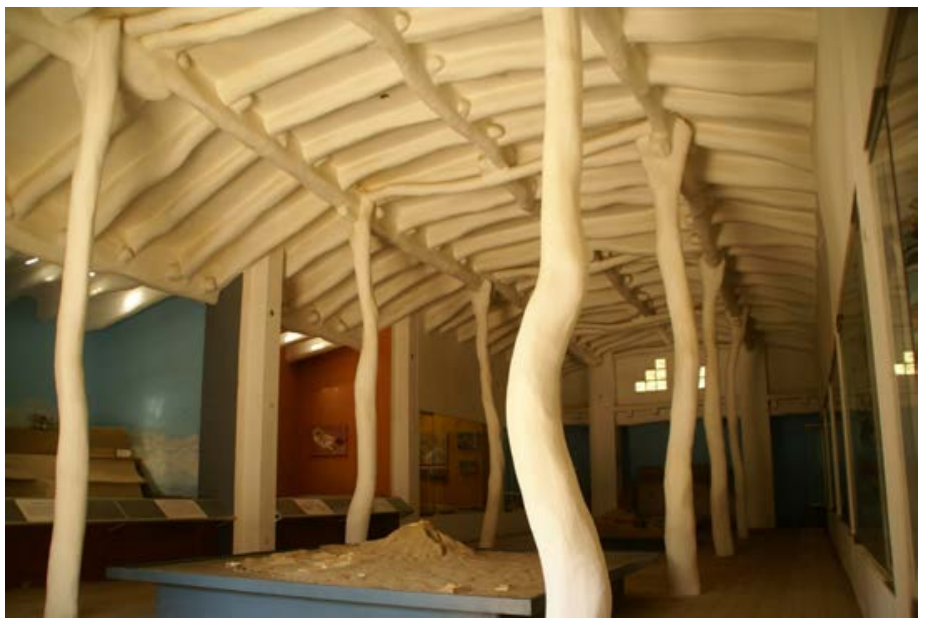

Figura 3. Sala principal del museo, 1994.

Main hall of the museum, 1994. 
abrieron las puertas a la cooperación internacional y a la universidad para realizar, primero, un proyecto de desarrollo comunitario y, después, participar en un concurso de proyectos dirigido a la generación de habilidades artesanales y de diseño en diversas líneas productivas. Para organizar y planificar este espacio educativo logramos la participación de Yolanda Maldonado, de nacionalidad portorriqueña y con amplia experiencia en programas educativos desde sitios patrimoniales, con quien compartimos la maestría en Kent. Gracias al interés de un operador de turismo internacional, ella viajó desde Italia a Túcume para trabajar con nosotros de manera honorífica y voluntaria, formando un equipo que hizo posible la planificación de un programa educativo en el año 2000 en el que participaron maestros de nuestra comunidad. Habíamos dado forma y creado el primer programa educativo permanente en el seno de un museo en el Perú. En él se formularon actividades creativas, lúdicas y entretenidas, sencillas por naturaleza, para lograr una estancia educativa e interesar no solamente a los niños de la comunidad sino involucrar a maestros y padres de familia. Actividades que hicieron posible el acercamiento al patrimonio cultural, no solo arqueológico, y que involucraron la preocupación por el ambiente en procura de mejores condiciones de vida. El reto era hacer del patrimonio parte de la vida cotidiana, ayudando a la generación de ingresos económicos directos para las familias interesadas y alentando la participación de género en una sociedad esencialmente machista. Se buscó también contribuir a la forja de líderes locales, integrar sin distingos y democratizar el conocimiento, evitando que circulara solamente en el ámbito de los especialistas.

En el rubro educativo decidimos incluir todas aquellas actividades relacionadas con servicios o producción de recuerdos y artesanía vinculadas al museo, el patrimonio arqueológico, la cultura tradicional y los valores de nuestro ambiente natural. En otras palabras, consideramos necesario hacer que el proceso educativo no solo incorporara aquellos discursos relacionados con los aspectos éticos y de ciudadanía para la conservación, sino también la organización y desarrollo de talleres que hicieran posible productos de alta calidad para el naciente mercado turístico local y regional, así como las principales ferias de promoción artesanal que tienen lugar en varias partes del país, especialmente en Lima.

Seguidamente, no dejamos pasar la oportunidad de articularnos en un gran proyecto con la Agencia Española de Cooperación Internacional, que permitió dar forma a los primeros productos, todos de muy alta calidad, dirigidos a la educación de los niños del nivel primario y luego secundario (Figuras 4 y 5). Con ello se hizo realidad una idea con la que nació el proyecto de museo, un esfuerzo para la gestión del conocimiento adquirido durante el proceso de investigación científica, realizado sobre la base de un amplio proceso de experimentación, de planificación participativa, de integración comunitaria y desarrollo educativo. Se abordaron temas con los que nos identificamos siempre, pero cuya comprensión alcanzó niveles importantes por lo aprendido en la Universidad de Kent, intercambiando ideas y propuestas con gestores de varias partes del mundo. Se publicaron tres cuadernos interactivos enfocados en los siguientes temas: tradiciones y costumbres, patrimonio natural y patrimonio arqueológico. Lo mismo se hizo para estudiantes de secundaria con dos productos complementarios: "Guías de Diseño" y "Guías de Proyectos", uno por cada grado de estudio. Todos fueron el resultado de la participación de especialistas en pedagogía, de diseñadores gráficos

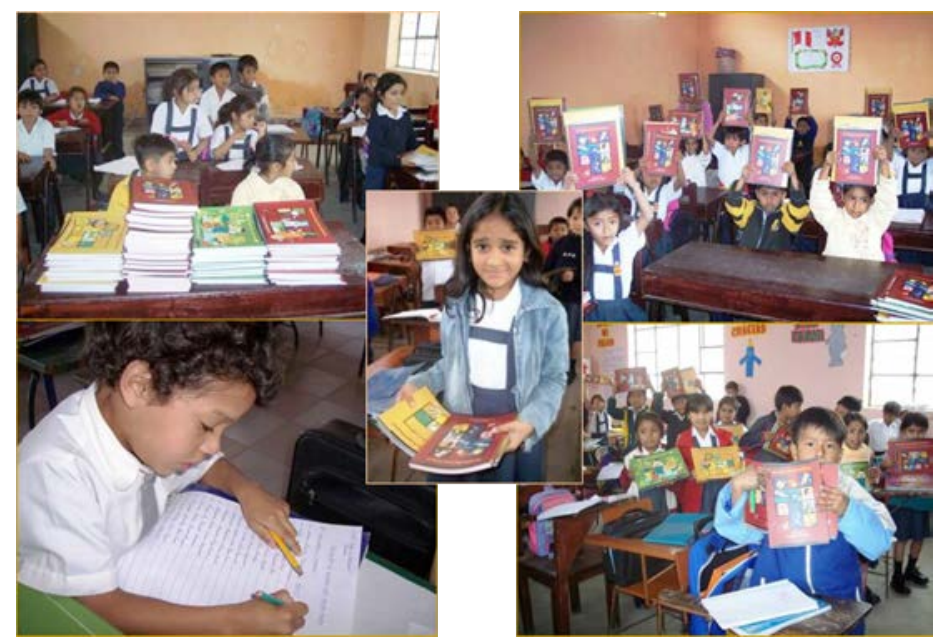

Figura 4. Distribución y uso de cuadernos interactivos en las escuelas.

En Inglés. Distribution and use of interactive notebooks in schools. 


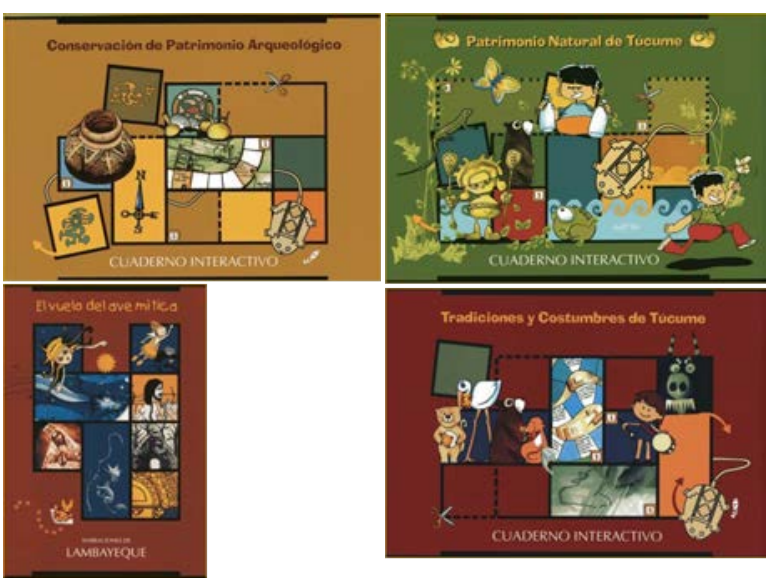

Figura 5. Los cuadernos interactivos para educación primaria.

The interactive notebooks for primary education.

y artistas plásticos de la Pontificia Universidad Católica del Perú, con el aporte del museo y la participación de maestros y escolares de nuestra comunidad.

$\mathrm{Al}$ paso de los años, los logros son significativos $\mathrm{y}$ pueden resumirse en los siguientes:

- La actividad institucional se ha nutrido de los lineamientos y propuestas incluidas en el "Plan de Manejo del Complejo Arqueológico Túcume y su Entorno Urbano y Rural" (que incluyen las propuestas académicas de nuestra tesis de Maestría en el DICE de la Universidad de Kent), que permite trabajar ordenadamente de acuerdo a las prioridades de sus cuatro programas: Patrimonio Cultural; Turismo Sostenible; Poblamiento Rural-Urbano y Educación para la Conservación. Este último nos ha permitido incorporar a la comunidad en planes conservacionistas, participando de modo entusiasta en la elaboración y ejecución de cada actividad y/o proyecto. Dicho documento fue financiado por el Ministerio de Comercio Exterior y Turismo a través del Plan Copesco Nacional y la Municipalidad de Túcume.

- El saqueo popular de los monumentos durante Semana Santa ha desaparecido completamente. El monumento dejó de ser una cantera o el basurero de la comunidad. - La Oficina de Educación para la Conservación del Museo (OFECOM) ha elaborado, de modo participativo e inclusivo, un programa educativo anual que permite la participación diaria de las escuelas. $\mathrm{Su}$ alcance es muy diverso: vivero, biohuerto, reciclaje, clínica de arqueología y conservación para niños, una productora de radio, un pueblo tradicional en miniatura, grupos de danzas locales y regionales, diversas líneas de artesanía (cerámica, textiles, juguetes, repujado en lámina metálica, máscaras, teñido en reserva, papel reciclado, mates, joyería, tintes naturales y un sistema de auditorios para cine, documentales, conferencias y talleres permanentes). Organiza excursiones, caminatas o paseos interpretativos. Promueve pasantías, el proyecto Tierra de Niños de la ONG Ania (Figura 6) y coordina el Directorio de Niños del museo, en el que participan los alumnos con las más altas calificaciones en las escuelas primarias de la comunidad (Figura 7). Este directorio adquiere una dinámica propia y paralela a la gestión oficial del museo. Decenas de centros educativos de Lima y otras regiones del país, organizan anualmente viajes dirigidos a participar del programa educativo como parte de las excursiones que realizan.

- Gracias a los aportes del Estado, se han realizado obras de infraestructura para el uso público y especialmente turístico, además de proyectos de investigación, conservación arquitectónica y de su colección de objetos muebles. Para estas actividades, el museo ha sido capaz de conseguir también fondos internacionales, fondos contravalor y aportes de empresas privadas administrados por un patronato integrado por empresarios de la capital de la región. Gracias a los aportes privados y del Estado el museo ha crecido exponencialmente, inaugurando nuevas instalaciones en 2014 con un edificio moderno que incorpora elementos de alta tecnología, sin embargo, conserva un discurso científico relacionado con el territorio, la comunidad y la continuidad cultural entre el pasado y el presente (Figura 8). Este museo, reivindica, hasta donde es posible, el espacio en el que ha sido edificado pues, este terreno arqueológico fue convertido en cantera, un atentado de lesa cultura producido por el Estado en el marco de un estado de emergencia por lluvias torrenciales en 1983.

- El museo ha logrado generar permanentemente publicaciones diversas, incluyendo temas especializados en arqueología, etnografía, educación, conservación y turismo.

- La actividad turística ha comenzado a cobrar importancia, logrando hasta el momento constituirse 


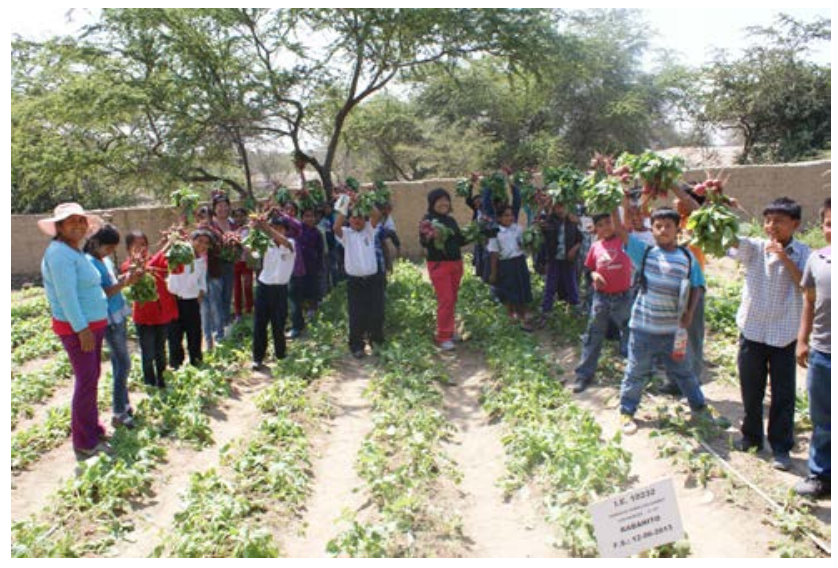

Figura 6. Cosechando los frutos de la tierra. Actividad del programa educativo del ecomuseo.

Harvesting the fruits of the land. Activity of the educational program of the museum.

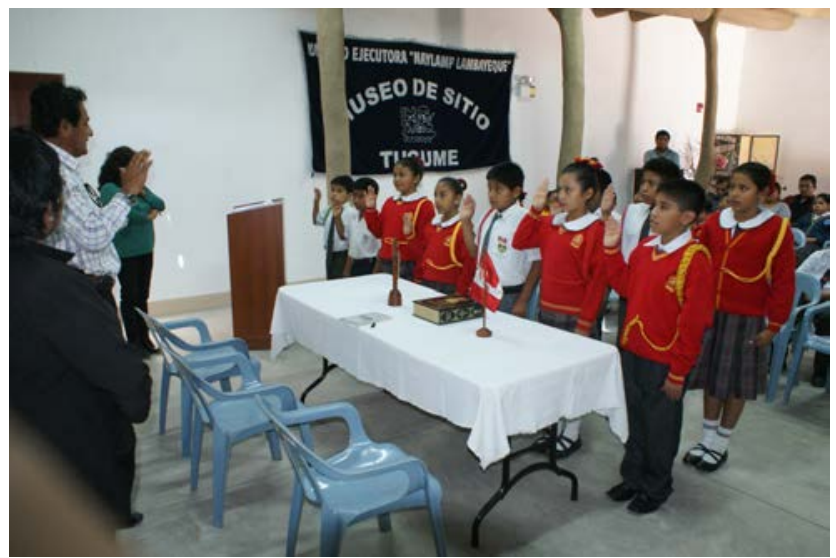

Figura 7. Directorio de niños del ecomuseo en ceremonia de compromiso. Board of children of the ecomuseum in commitment ceremony.

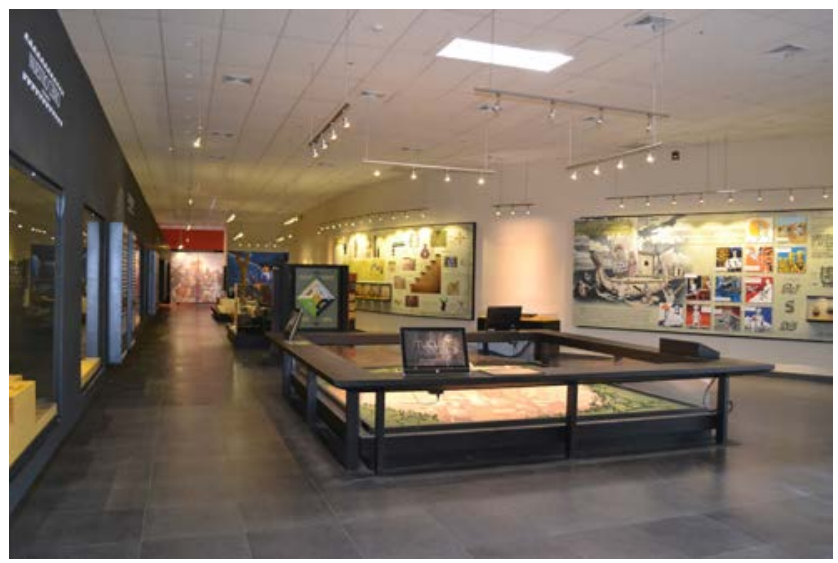

Figura 8. Interior de una de las salas del nuevo museo, 2014. Inside of one of the rooms at the new museum, 2014. 
en el segundo centro de interés en Lambayeque, luego del Museo Tumbas Reales de Sipán. Un flujo cercano a los 65.000 usuarios al año (2016), ha comenzado a generar diversas oportunidades de negocios para las familias integradas en las distintas áreas del museo. Se espera que las nuevas instalaciones para la visita de ciertas secciones del monumento contribuyan a despertar un mayor interés y un flujo creciente de visitantes.

\section{El Ecomuseo Túcume}

Al culminar el Proyecto Arqueológico Túcume en 1994 con la fundación del Museo Túcume, pusimos en práctica, por primera vez en el Perú, los principios de la Nueva Museología francesa que estuvo en boga en otras latitudes y la consideramos como un especial regalo. Este texto es inspirador y magistral por donde se lo mire, resumiendo a la perfección desde una mirada antropológica nuestras propias ideas sobre el sentido de un museo y la gestión del patrimonio arqueológico. El texto es el siguiente:

Un ecomuseo es un instrumento que un poder público y una población conciben, fabrican y explotan conjuntamente...

Un espejo en el que esa población se mira, para reconocerse en él, donde busca la explicación del territorio al que está unido, junto al de las poblaciones que la han precedido, en la discontinuidad o la continuidad de las generaciones. Un espejo que esa población presenta a sus huéspedes, para hacerse comprender mejor, en el respeto a su trabajo, sus comportamientos, su intimidad.

Una expresión del hombre y de la naturaleza... Una expresión del tiempo [...] que juegue, en este caso, un papel de información y de análisis crítico.

Una interpretación del espacio. De espacios escogidos, donde el visitante pueda reposar, o caminar.

Un laboratorio, en la medida en que contribuye al estudio histórico y contemporáneo de esa población y de su medio...

Un conservatorio, en la medida en que ayuda a la preservación y a la valoración del patrimonio natural y cultural de esa población.

Una escuela, en la medida en la que asocia a esa población con sus acciones de estudio y de protección, en la que incita a un mejor análisis de los problemas de su propio futuro.
Ese laboratorio, ese conservatorio y esa escuela se inspiran en principios comunes. La cultura que ellos invocan hay que entenderla en su sentido más amplio, al tiempo que se consagran a dar a conocer la dignidad y la expresión artística de las diversas capas de población de las que emanan las diferentes manifestaciones. En el ecomuseo la diversidad no tiene límites, habida cuenta de las diferencias existentes.

La población no se encierra en sí misma, sino que recibe $\mathbf{y}$ da.

22 de enero de 1980 (Rivière 1993:191-192; el texto en negrita es nuestro).

Con ese mismo espíritu nos acercamos a este territorio, tratando de mantener un proceso de permanente vinculación al patrimonio cultural, buscando no solo su conservación sino su uso en diversos campos: educación escolar, exploración y aprendizaje de tecnologías ancestrales, recuperación de las tradiciones orales campesinas, gastronomía, saberes productivos y revaloración de diversos aspectos de música y danza local, especialmente relacionadas con el factor religioso.

El Museo Túcume, en el marco de un proceso de "globalización" creciente como expresión del siglo XXI, promueve de modo constante la presencia del patrimonio cultural en la vida cotidiana, la conservación ambiental y el desarrollo de buenas prácticas. Hoy el Ecomuseo Túcume, es un espacio abierto y libre, un foro de encuentro en el que se asumen responsabilidades colectivas. Fue consecuencia de una decisión en la que participaron 41 instituciones y organizaciones locales, que hoy promueven actividades conjuntas y tienen como objetivo el desarrollo local sobre la base del patrimonio cultural (Figuras 9 y 10). El ecomuseo tiene cinco áreas de trabajo especializadas con diversa participación:

- Patrimonio Cultural, integrado por maestros curanderos, grupos de danza y teatro locales, clubes deportivos, el Museo Túcume y radios locales (Figuras 11, 12 y 13).

- Ambiente, Agricultura y Paisaje, con agricultores organizados interesados en cultivos orgánicos: Amigos del Bosque Seco (AMIBOSE) de la Comunidad Santa Rosa de las Salinas y la Asociación APRODI (Asociación de Productoras Diversificadas) Akafala, integrada por esposas de agricultores de la Junta de Regantes (Figura 14).

- Turismo, con la participación del Club de Turismo local, Casa Federico Villareal, Asociación 


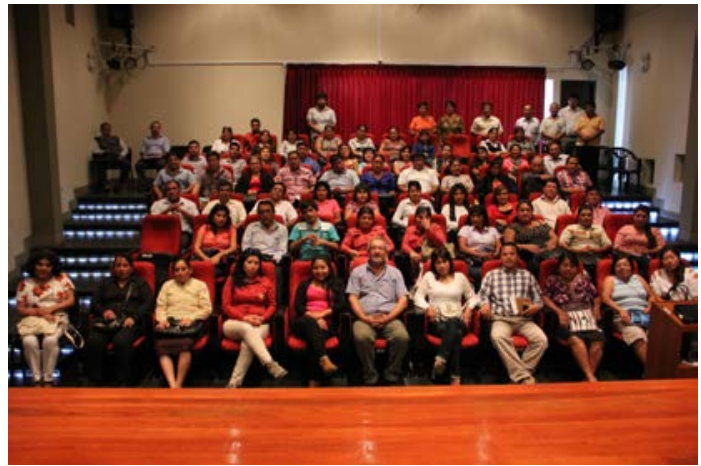

Figura 9. Integrantes del Ecomuseo Túcume el día de su creación, en el auditorio.

Members of the Túcume Ecomuseum on the day of its creation, in the auditorium.

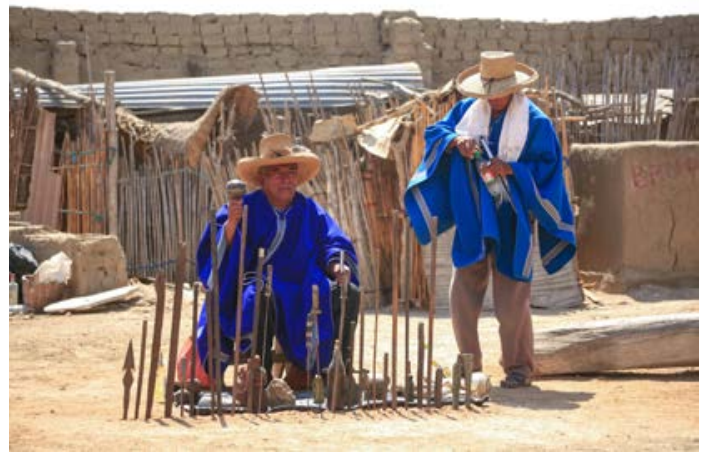

Figura 11. Don Gerardo Nima, un maestro curandero del ecomuseo.

Gerardo Nima, a master healer of the museum.
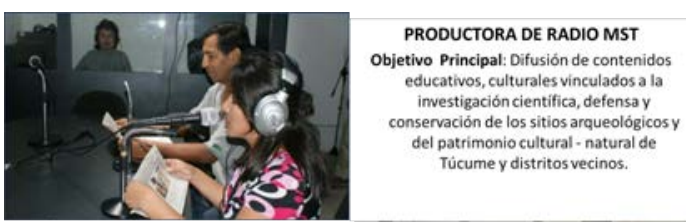

PRODUCTORA DE RADIO MST Objetivo Principal: Difusión de contenidos educativos, culturales vinculados a la investigación cientifica, defensa y conservación de los sitios arqueológicos $y$ del patrimonio cultural - natural de Túcume y distritos vecinos.
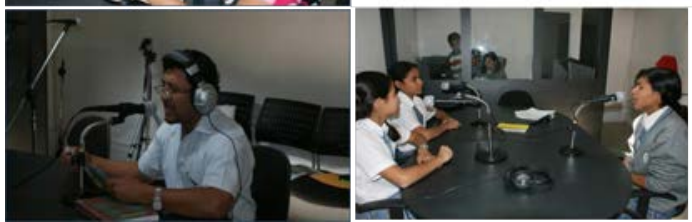

Figura 13. Productora radial del Museo Túcume. Radio producer of the Túcume Museum.

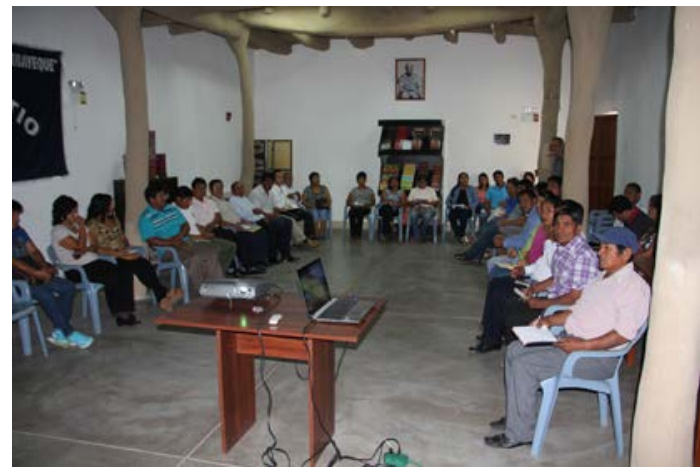

Figura 10. Sesión ordinaria del ecomuseo.

Regular meeting of the ecomuseum.

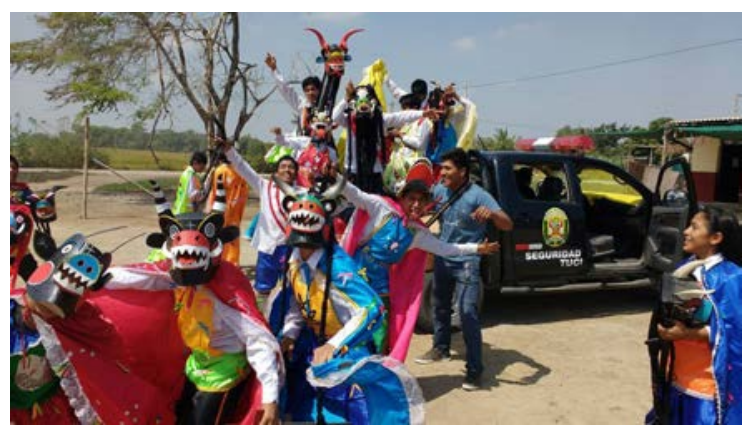

Figura 12. El grupo de danzas locales del ecomuseo. Local dance group of the ecomuseum.

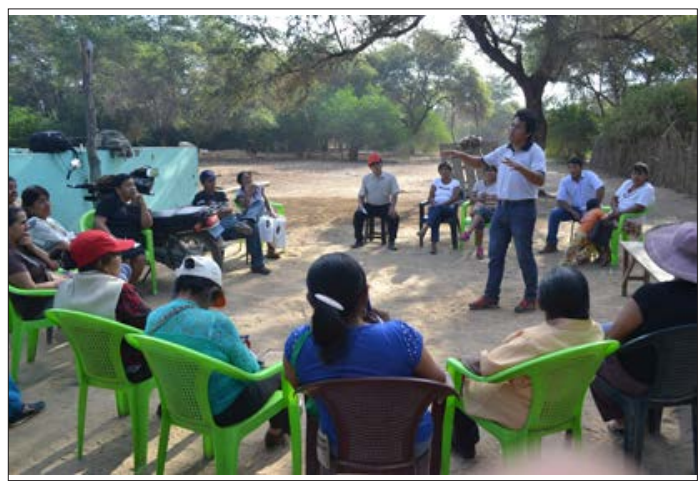

Figura 14. El ecomuseo en talleres de capacitación en caseríos rurales.

The ecomuseum in training workshops in rural hamlets. 
Gastronómica de Túcume, asociaciones de artesanos, transportistas locales, guías de turismo y hospedajes locales (Figura 15).

- Educación, formado por la Red de Maestros Innovadores, organización de 15 directores de centros educativos estatales, y la OFECOM (Figura 16).

- Planeamiento Rural y Urbano, integrado por la Municipalidad, Gobernación, Policía Nacional y

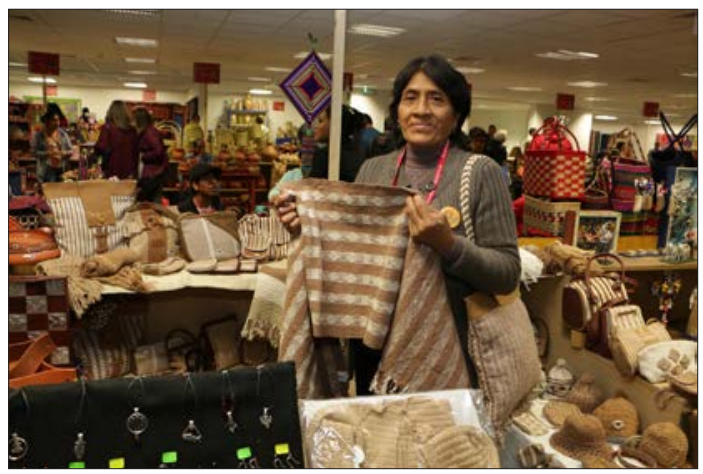

Figura 15. Artesanos del ecomuseo en la feria nacional Rurak Maki del Ministerio de Cultura.

Artisans of the ecomuseum in the Rurak Maki national fair of the Ministry of Culture.

lo que el Estado y las normas obligan. Las actividades educativas del museo contribuyen a este proceso. A lo largo del tiempo, hemos logrado que el museo se convierta en una casa de la comunidad que despierta el interés permanente de los vecinos, la mayoría de los cuales son campesinos. Esto se ha convertido en motivo de interés de voluntarios internacionales, estudiantes universitarios y especialistas en gestión cultural, así como tema de numerosas de tesis de grado y post grado en diversos aspectos académicos: educación, comunicación para el desarrollo, gestión de patrimonio, etnografía, arqueología, turismo sostenible y artesanía. Un patronato, formado por destacados empresarios de la ciudad de Chiclayo, garantiza un escenario de contribución de recursos del sector privado nacional e internacional que, felizmente, apoya este proceso de modo permanente.

\section{Conclusiones}

El viejo modelo de un museo concebido únicamente como un edificio que alberga una colección de objetos para el disfrute de un público interesado o especializado y los turistas, cambió en Túcume hace 25 años por uno que privilegia el territorio, la comunidad y el patrimonio cultural de esa región. A pesar de comités de base de los asentamientos organizados por el museo.

De este modo, las principales organizaciones de la comunidad hacen posible vincular un número cada vez mayor de personas con el patrimonio cultural y arqueológico, identificándose con él y adquiriendo motivaciones suficientes para protegerlo, más allá de

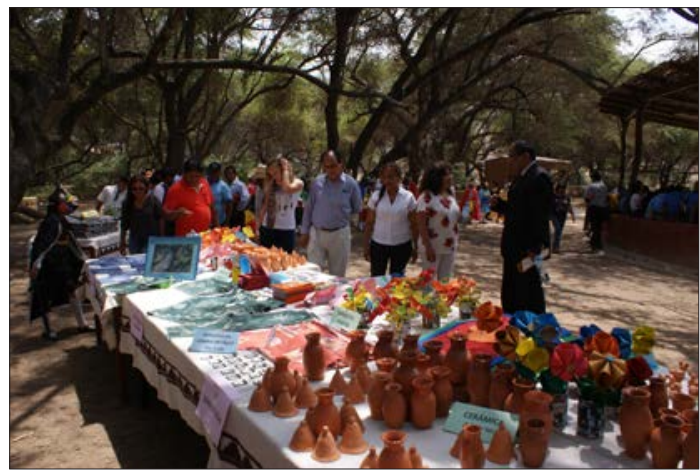

Figura 16. Feria de productos del programa educativo con las escuelas locales.

Fair for products of the educational program with the local schools.

nuestras permanentes limitaciones, sabiendo que las dificultades económicas y financieras son enormes, se han alcanzado grandes logros en la incorporación comunitaria en diversos aspectos relacionados con la educación, la conservación y la gestión del patrimonio. Sin embargo, los retos son muy grandes pues aún son grandes los problemas, especialmente en los ámbitos de ciudadanía y calidad ambiental. Pero, qué duda cabe, éste es un modelo que ha encontrado colectivamente alternativas para la gestión y manejo de nuestro patrimonio cultural, empoderando a la comunidad y buscando un soporte en el turismo sostenible. Estos 25 años nos permiten esbozar algunas propuestas para hacer viables procesos como éste:

- Generar conocimiento científico y diseñar una estrategia de gestión de dicho conocimiento. El saber no circula solo en el ámbito de los especialistas: se inscribe como parte del desarrollo comunitario. Así, la ciencia se democratiza y el patrimonio arqueológico se hace visible y tangible.

- Aprender a ser gestores de nuevo tipo como parte de una responsabilidad del Estado y particularmente del Ministerio de Cultura y las universidades. Los sitios y museos deben tener una apertura al territorio y la comunidad, asumiendo que el museo 
es más que un edificio y una colección exótica. - Incorporar a la sociedad en la gestión del patrimonio, promoviendo formalmente los conceptos teóricos de la educación para la conservación desde los sitios y museos. Se trata de una educación creativa, crítica, lúdica, entretenida y divertida que genere compromisos y liderazgo. La conservación del patrimonio arqueológico sin la participación de las comunidades locales es una ilusión.

- Generar una integración económica y productiva a nivel local, a partir de la salvaguarda y conservación del patrimonio natural y cultural. Con base en el patrimonio se pueden realizar actividades productivas o de servicios, promover empleo, crear microempresas familiares y luchar contra la pobreza y discriminación de género.

- Definir planes estratégicos consensuados, indispensables porque marcan una ruta y establecen indicadores claros y medibles para evaluar el avance de las políticas de gestión.

- Establecer alianzas de largo aliento que fomenten la participación de la empresa privada en los programas y proyectos vinculados con la investigación y la conservación del patrimonio cultural, en colaboración con municipios y gobiernos regionales.

- Generar fondos de emergencia permanentes de prevención para proteger a los monumentos ante la presencia de desastres naturales, en especial los efectos de las lluvias torrenciales en la costa sobre monumentos y asentamientos de adobe.

- Finalmente, consideramos muy importante emprender gestiones de largo aliento, de naturaleza técnica y basadas en los nuevos conceptos de gestión sostenible y buenas prácticas. En este marco, los cambios generacionales deben ser adecuados y oportunos, sin perder la continuidad del proceso.

Somos conscientes que este camino no tiene retorno y estamos seguros que alguna vez llegaremos a lo alto de la montaña, como un símbolo del esfuerzo de una comunidad y su museo, que no se rinden ante las dificultades y aspiran por un futuro mejor.

\section{Referencias Citadas}

Alva, W. (s/f). Sipán. Descubrimiento e Investigación. Promperú, Lima.

Delgado Elías, B. y L.A. Narváez Vargas 2015. Programa de educación para la conservación. Museo Túcume. Perú. En Best Practice 4. A Tool to Improve Museum Education Internationally, editado por E. Nardi y C. Angelini, pp. 141-142. Edizioni Nuova Cultura, Roma.

De Varine-Bohan, H. 1985. El ecomuseo más allá de la palabra. Museum 148 (XXXVII, 4):185.

Heyerdahl, S. y L.A. Narváez Vargas 1994. The Pyramids of Túcume The Quest of a Forgotten City. Editorial Thames and Hudson, Londres.

Heyerdahl, S., L.A. Narváez Vargas y L. Millones 1995. Túcume. Colección Artes y Tesoros del Perú. Banco de Crédito del Perú, Editorial Ausonia, Lima.

Narváez Vargas, L.A. 1996a. El sector monumental. En Túcume, editado por T. Heyerdahl, pp. 83-151. Colección Artes y Tesoros del Perú, Banco de Crédito del Perú, Lima.

Narváez Vargas, L.A. 1996b. La conexión marítima. En Túcume, editado por T. Heyerdahl, pp. 153-165. Colección Artes y Tesoros del Perú, Banco de Crédito del Perú, Lima.

Narváez Vargas, L.A. 2000a. Dioses, Encantos y Gentiles. Introducción al Estudio de la Tradición Oral Lambayecana.
Ediciones del Museo de Sitio Túcume, Instituto Nacional de Cultura, Lambayeque.

Narváez Vargas, L.A. 2000b. Establishing Community Involvement in Tourism and Conservation. A Case Study. Túcume. Perú. Tesis para optar el grado de Magíster en Ciencias, Durrel Institute of Conservation and Ecology, Kent University, Canterbury.

Narváez Vargas, L.A. 2014. Los Diablos de la Virgen. Ediciones del Museo de Sitio Túcume, Unidad ejecutora 005, Ministerio de Cultura, Chiclayo.

Narváez Vargas, L.A. y B. Delgado Elías 2007. Túcume: Una Experiencia de Apropiación Social del Patrimonio Cultural en el Valle de Las Pirámides - Lambayeque- Perú. Convenio Andrés Bello y Museo de Sitio Túcume, Patronato del Valle de las Pirámides de Lambayeque, Chiclayo.

Rivière, G.H. 1993. La Museología. Curso de Museología. Textos y Testimonios. Editorial Akal, Madrid.

Tavera Vega, L. s/f. Túcume. Arqueología del Perú.http://www. arqueologiadelperu.com.ar/ tucume.htm.

Zevallos Quiñónez, J. 1994. Huacas y Huaqueros en Trujillo durante el Virreynato, 1535 - 1835. Editorial Normas Legales, Trujillo.

\section{Notas}

${ }^{1}$ Se trata de una Virgen Grande que ocupa su lugar en el templo principal del área urbana de Túcume, cuya atención es responsabilidad masculina, y una Virgen Chica conocida como la Andariega o la Ingrata, que camina por el área rural todo el año visitando casas y caseríos para retornar durante las fiestas en su honor: la principal en febrero, coincidiendo con el carnaval, y la Fiesta de Medio Año en el mes de setiembre, cuando inician los preparativos de limpieza de canales para esperar la llegada de la estación húmeda a fin de año. La Virgen Chica está a cargo solamente de mujeres.
${ }^{2}$ Mesa rústica con soportes de madera y tablero hecho con una parrilla de caña cubierta con barro. En la parte central se construye un fogón de adobe bien enlucido, de variadas dimensiones.

${ }^{3}$ Espacio doméstico dedicado a la producción de chicha de maíz

${ }^{4}$ Término que se usa para consumir comida rápida y tradicional, para que varias personas puedan "picar" de una sola fuente. Implica, además, el picante del ají que llama a mayor consumo de chicha y mejora el negocio. 